\title{
Nasal Tip Projection: Asymmetries after Rhinoplasty
}

\author{
Gabriela Kopacheva-Barsova ${ }^{1 *}$, Nikola Nikolovski ${ }^{1}$ Maja Kirjas ${ }^{1}$, Aleksandar Avramovski \\ ${ }^{1}$ University Clinic for Ear, Nose and Throat, Faculty of Medicine, Ss Cyril and Methodius University of Skopje, Skopje, \\ Republic of Macedonia; 'Policlinic "Akus Medikus", Skopje, Republic of Macedonia
}

\begin{abstract}
Citation: Kopacheva-Barsova G, Nikolovski N, Kirjas M, Avramovski A. Nasal Tip Projection: Asymmetries 6(2):158-161 5773.2013.0290.

Key words: Nasal tip asymmetries; rhinoplasty; facial planning; major secondary revision procedures; minor secondary revision procedures.

"Correspondence: Gabriela Kopacheva-Barsova, MD. University Clinic for Ear, Nose and Throat, Faculty of Medicine, Ss Cyril and Methodius University of Skopje, Skopje, Republic of Macedonia. E-mail: gabrielak70@yahoo.com

Received: 14-Feb-2013; Accepted: 22-Mar-2013; Online first: 29-Mar-2013

Copyright: () 2013 Kopacheva-Barsova G. This is an open-access article distributed under the terms of the Creative Commons Attribution License, which permits unrestricted use, distribution, and reproduction in any medium, provided the original author and source are credited.

Competing Interests: The authors have declared that no competing interests exist.
\end{abstract}

\begin{abstract}
Background: Nasal tip projection has been defined as the distance along a perpendicular line from the vertical facial plane to the most anterior projecting point of the nasal tip. The tripod concept, although an oversimplification of nasal tip dynamics, highlights the intimate relationship between projection and rotation.

Aim: The aim of the study was to evaluate the rate of nasal tip irregularities after the medial crura overlay procedure, and following the Tripoid concept.

Methods: We completed a retrospective review of patients who have been admitted at ENT Clinic, Skopje from the period of 2008-2012. Operative technique rhinoplasty was prepared in 36 patients. Procedures included full-transfixion incision, release of tension septum, lateral crural overlay (LCO), dome truncation, medial crural overlay (MCO), and combinations of them. We reviewed major and minor secondary revision procedures that patients underwent, postoperative complications, and any functional complaints.

Results: Of the remaining 36 patients: one $(2.5 \%)$ required minor revision of dorsal irregularities, $3(3.0 \%)$ required tip revision, 33 patients $(93.3 \%)$ were satisfied without qualification, 3 patients $(3.5 \%)$ were not satisfied and wont for revision surgery. Three patients $(2.5 \%)$ underwent radix grafts. $5(13.3 \%)$ of the patients had had previous rhinoplasty performed by another physicians. Seven patients $(18.3 \%)$ were classified as having tension nose. One patient had postoperative epistaxis, and there were no cases of postoperative functional complaints.
\end{abstract}

Conclusion: Our revision rate of $4.2 \%$ for tip irregularity and our finding that no patients had postoperative functional complaints allows us to feel confident that this algorithmic paradigm can be used to accomplish tip deprojection in almost any circumstance.

\section{Introduction}

Nose, as the central feature of the face has a profound effect on facial aesthetics. Nasal tip projection must be not only in relation to the nasal dorsum but also in relation to overall facial proportions. Rhinoplasty maneuvers can increase, preserve, or decrease nasal tip projection. Therefore, they can be chosen properly [1-3].

Today, we still defined the classic facial aesthetic for the nose which is based on a GrecoRoman ideal. But, modern aesthetic values depend of multicultural nature of society and of beauty. Greater focus is placed on improving nasal and facial aesthetics while preserving nasal and facial ethnicity. We suggested that the important role is "too look like natural", so the modern trend is a stronger nasal profile and a more natural, "unoperated" look [4-6].

Nasal tip projection after rhinoplasty is depending of several factors: first is nasal tip projection which has been defined as the distance along a perpendicular line from the vertical facial plane to the most anterior projecting point of the nasal tip. Numerous reports have not only defined the proportions and angles that constitute the aesthetic ideal but also developed formulas to determine how closely an individual patient matches these aesthetic ideals [7-10].

Computer-generated image describe a nasal projection as derived by analysis by Crumley and Lanser.Their results defined an ideal ratio using the 
length from nasion to upper vermilion-cutaneous junction of the upper lip compared with the length of a perpendicular from this line to the tip-defining point.Computer-generated image depicts ideal nasal projection as derived by analysis by Crumley and Lanser [10].

The Tripod concept: described that each lateral crus composes one lateral leg of the tripod, and the paired medial crura constitute the central leg. Alterations in any of the tripod limbs change the spatial position of the nasal tip. The tripod concept although is used as an oversimplification of nasal tip dynamics, highlights the intimate relationship between projection and rotation. The tripod concept also highlights the effect of operative procedure on one limb may have on the spatial position of the entire nasal tip (Fig. 1) [11, 12].

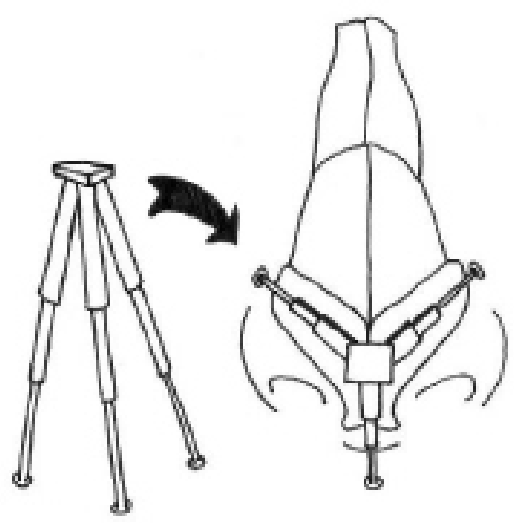

Figure 1: The Tripod concept.

The aim of the study was to evaluate the rate of nasal tip irregularities after the medial crura overlay procedure, and following the Tripoid concept.

\section{Material and Methods}

We completed a retrospective review of patients who have been admitted at ENT Clinic, University Hospital in Skopje from the period of 20082011. Operative technique rhinoplasty was prepared in 36 patients. Procedures included full-transfixion incision, release of tension septum, lateral crural overlay (LCO), dome truncation, medial crural overlay (MCO), and combinations of them. Patients underwent preoperative and postoperative evaluation during this period on a regular basis to record the effects of various approaches on nasal projection, rotation, need for revision, and patient satisfaction.We reviewed major and minor secondary revision procedures that patients underwent, postoperative complications, and any functional complaints.

Facial analysis: We have to demonstrate the importance of the radix nasi in aesthetic analysis. The height and position of the radix affect each other, define the nasofacial angle, and serve as the counterpoise of the nasal base. The importance of the radix nasi and the nasofacial angle in profile view are depending of position of: doral hump, nasal length, naso-frontal angle, nasofacial angle and nasolabial angle which is important of symmetry of nasal tip in a plenty of tip rotation operative techniques. The other factors which are affecting nasal appearance are: chin projection, contour of the lips and subnasale area (Fig. 2).

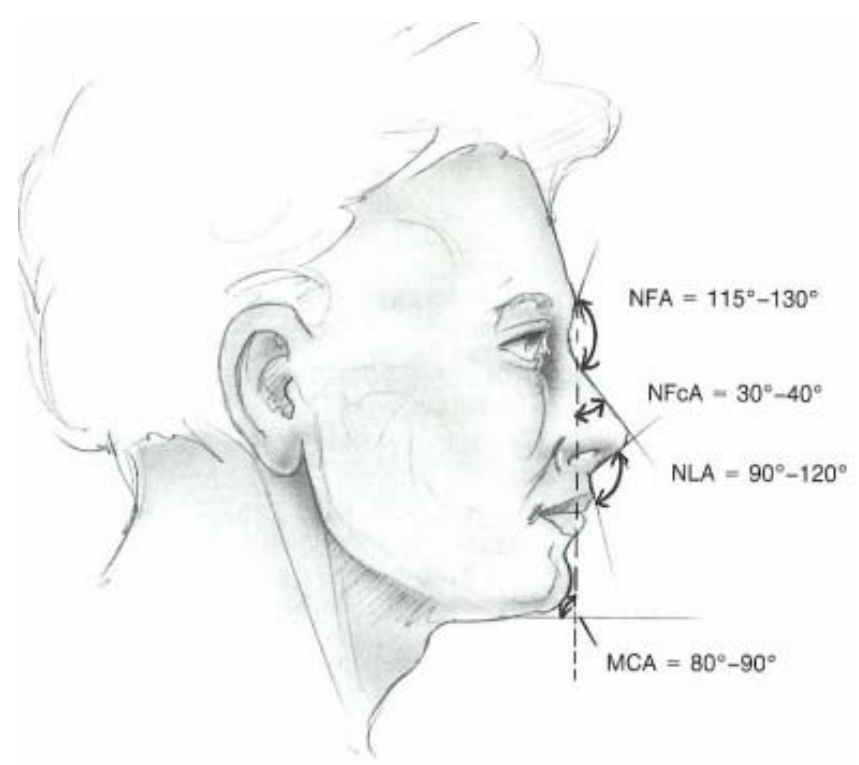

Figure 2: The tip projection and the nasal profile.

A final method which is evaluating nasal projection is the amount of nasal projection in relation to the upper lip. Ideal nasal projection is present when $50-60 \%$ of the horizontal projection of the nose is anterior to the upper lip as measured by a horizontal line drawn from the alar-facial groove to the tipdefining point and a perpendicular line drawn vertically to the most anterior projection of the upper lip.

The frequency of nasal tip surgery has become significantly more complex since the introduction of tip grafting and the many suture designs that followed open rhinoplasty. Two nasal tip features require mandatory preoperative identification: when the tip is adequately projecting and when the alar cartilage lateral crura isorthotopic or if they are cephalically rotated (malposition).

Only $33 \%$ of the patient population had adequate preoperative tip projection, and only $54 \%$ had orthotopic lateral crura. $46 \%$ percent of the patients had lateral crura that were cephalically rotated.

In every rhinoplasty, tip projection must first be assessed as normal, excessive, or deficient. The surgical goal is to preserve, to enhance, or to decrease tip projection. Most of the standard rhinoplasty incisions and maneuvers weaken the tip support mechanisms, which must be considered in surgical planning. If retrodisplacement of the tip and 
loss of projection is undesirable, these tip support mechanisms must be reconstituted.

\section{Results}

From 2008 to 2012, 36 patients were operated in one or more of preferred methods to treat overprojection of the nasal tip. We excluded patients who had undergone two previous rhinoplasty procedures before our attempts at correction.

In remaining 36 patients we founded out that: one $(2.5 \%)$ required minor revision of dorsal irregularities, $3(3.0 \%)$ required tip revision, 33 patients $(93.3 \%)$ were satisfied with their nasal tip without qualification, 3 patients $(3.5 \%)$ were not satisfied and wont for revision surgery, 3 patients $(2.5 \%)$ underwent radix grafts, $5(13.3 \%)$ of the patients had had previous rhinoplasty performed by another physicians, 7 patients $(18.3 \%)$ were classified as having tension nose (Figure 3 ).

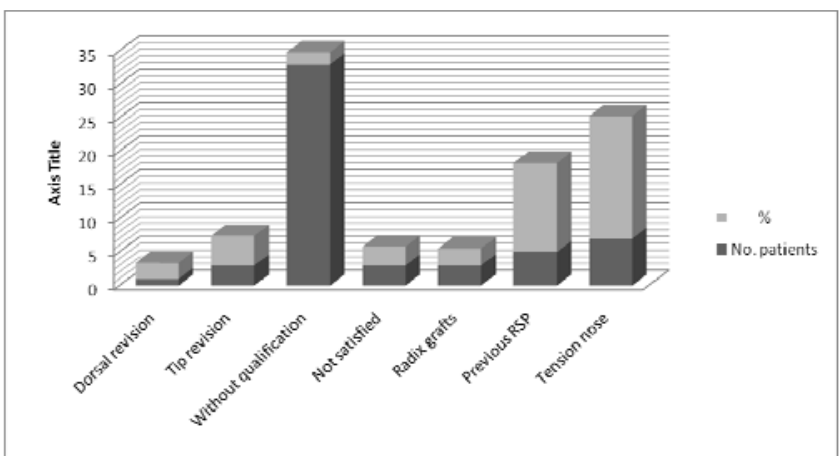

Figure 3: Types if asymmetries and previous operative procedures.

In postoperative period only one patient had postoperative epistaxis, and there were no cases of postoperative functional complaints (Figure 4).

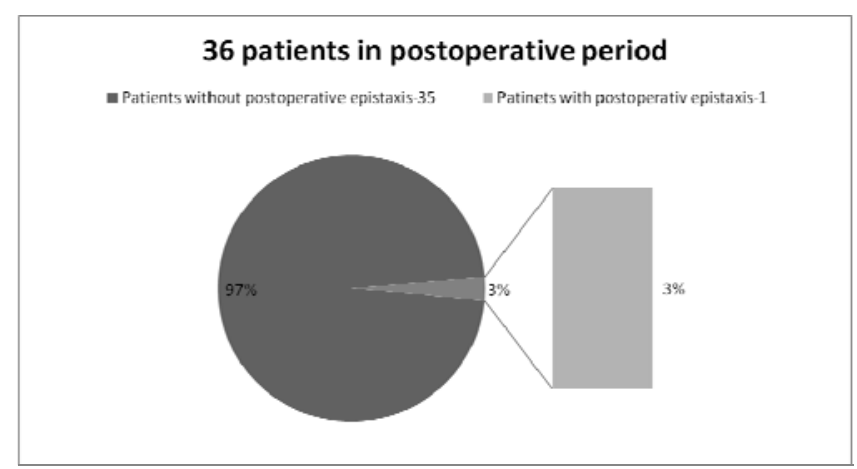

Figure 4: Postoperative complications and complains.

Concerning operative techniques, fulltransfixion incisions were made in 29 patients $(80.5 \%), 14(39.2 \%)$ underwent LCO, 4 patients $(9.2 \%)$ underwent MCO, 3 patients $(7.5 \%)$ underwent a combination of LCO and MCO, 5 patients (12.5\%) underwent dome truncation (Figure 5). In our study we reported same cases from our practice:

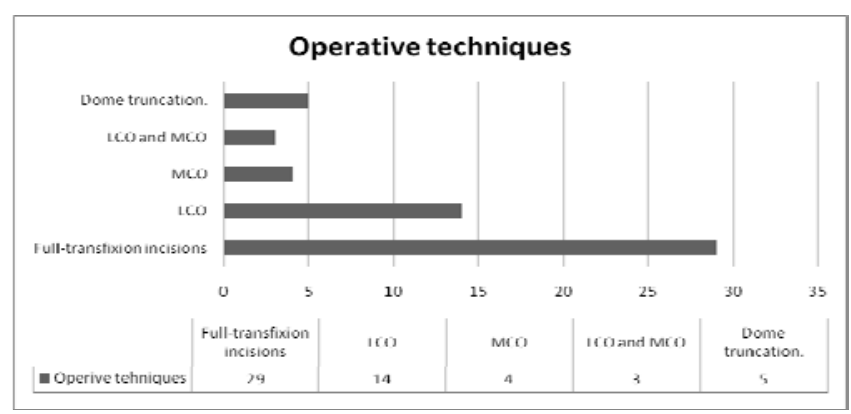

Figure 5: Types of operative techniques.

- We reported about 36 old year woman with "Double corn" tip, Rhinokyphosis, and nasal septal deviation. Closed approach was prepared, reducing of the nasal hump. Medial and lateral osteotomy was prepared and septalmedioposition. After we made resection of lateral alar cartilages for alar rim grafts. At the and we made tip reconstruction with dome suturing (Figure 6).
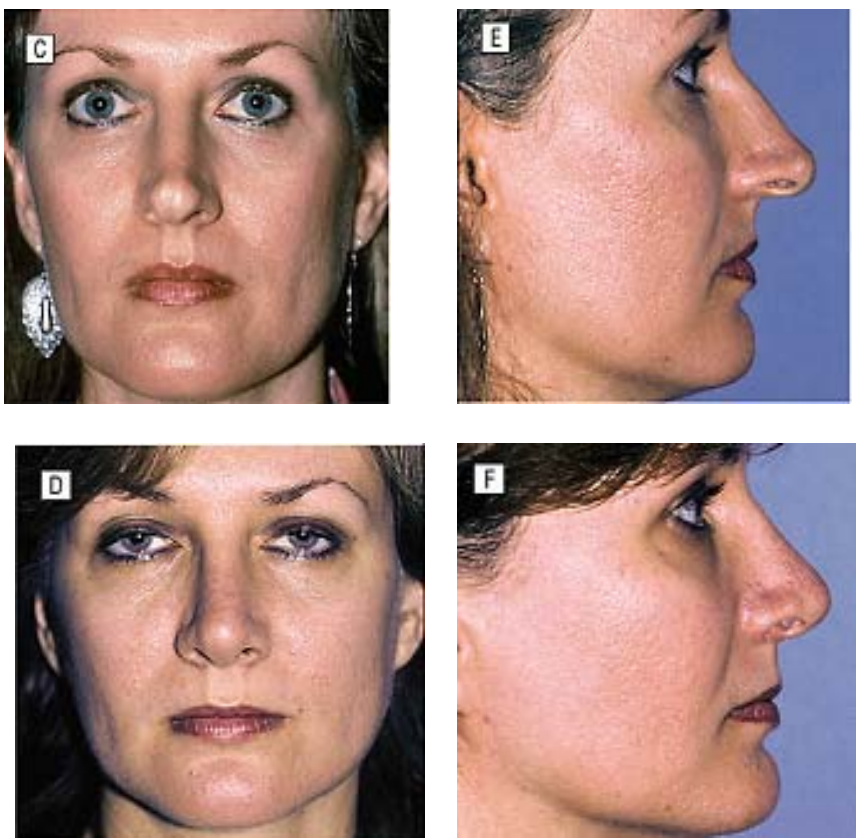

Figure 6: "Double corn" tip, Rhinokyphosis, and nasal septal deviation.

- Thirty two years old woman with nasal septal deviation, Rhinokyphosis and tension nose tip. We prepared closed approach with septalmedioposition. Medial and lateral osteotomy was prepared with cranial rotation and refinement of the nasal tip, after nasal hump reduction (Figure 7 ).
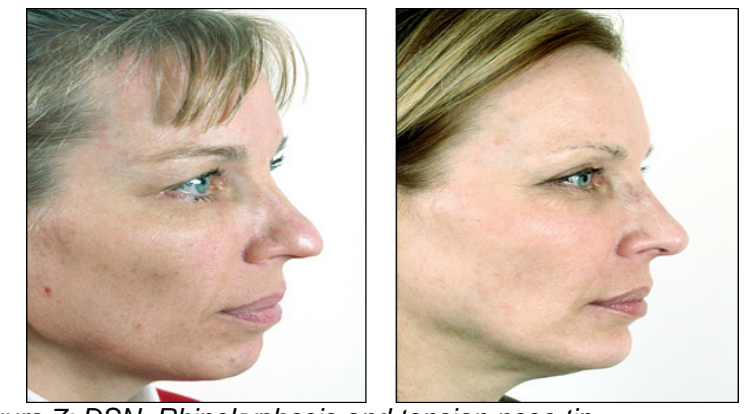

Figure 7: DSN, Rhinokyphosis and tension nose tip. 
- Girl, 26 years old with dropped tip, Rhinokyphosis and nasal septal deviation. Dorsal reduction without tip grafting will result in nasal deprojection because of antilever point modification. We made dorsal reduction and tip correction (Figure 8).

- Twenty seven years old girl with nasal septal deviation and nasal tip ptosis. Tip was "pulled" by nasal hump. We prepared closed approach with tip reconstruction,
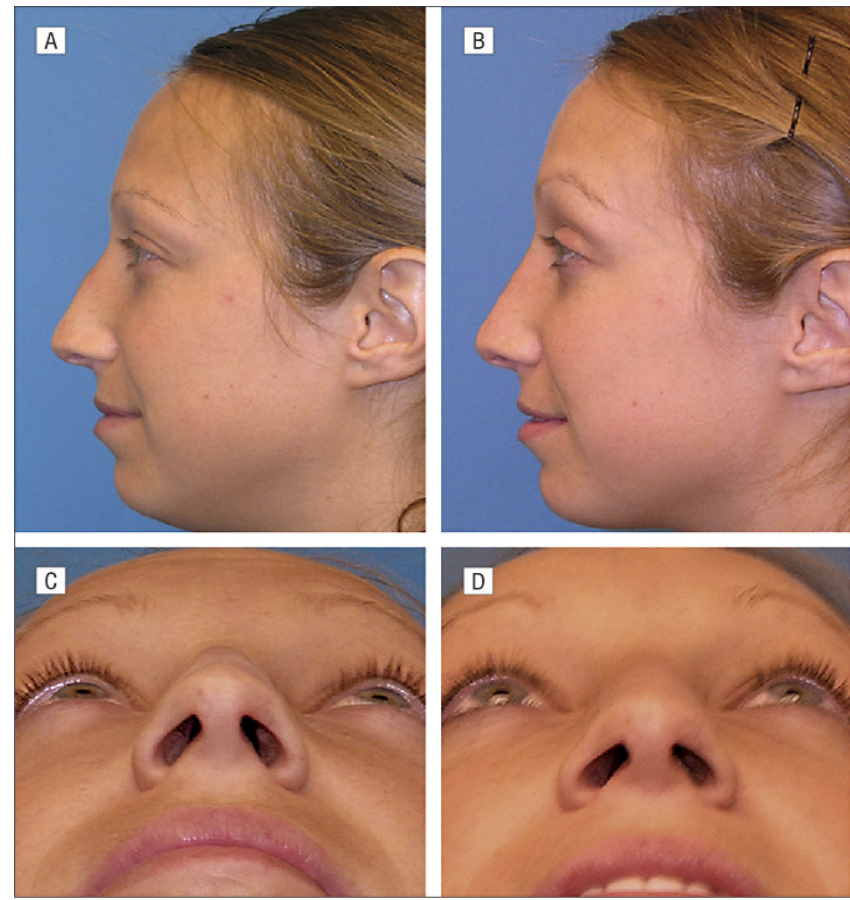

Figure 8: Dropped tip, Rhinokyphosis and DSN.

septalmedioposition. Hump removed. Medial and lateral osteotomy was prepared (Figure 9).

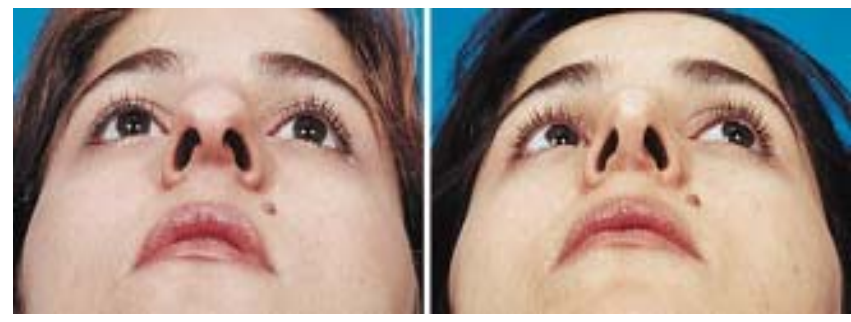

Figure 9: Nasal tip ptosis. Tip "pulled" by nasal hump.

\section{Discussion}

The overall surgical principles involved in the treatment of the nose projection and tip asymmetries were clearly elucidated by Tardy et al. He suggested that in all cases the surgeon can reduce excessive tip support mechanisms, reduce overdeveloped anatomic components, and normalize adjacent anatomic components at the and. Numerous authors have pointed to the tripod theory and suggested that when the medial crura are shortened in relation to the lateral crura, there would be a high tendency for alar flaring $[13,14]$.

\section{Conclusion}

In our finding we prepared medial crura overlay (MCO) in the most of the cases. And, according to the results we didn't reported too many cases with after surgery tip asymmetries or other nasal tip complications. In fact, no cases when MCO was used alone necessitated alar base reduction. Even more surprising was our finding that in our entire experience with deprojection, only $7.5 \%$ of the patients needed alar base reduction, and many of these patients desired this reduction before deprojection. As with any rhinoplasty, tip asymmetries can arise.

However, our revision rate of $4.2 \%$ for tip irregularity and our finding that no patients had postoperative functional complaints allows us to feel confident that this algorithmic paradigm can be used to accomplish tip deprojection in almost any circumstances.

\section{References}

1. McCollough EG, English JL. A new twist in nasal tip surgery: an alternative to the Goldman tip for the wide or bulbous lobule. Arch Otolaryngol. 1985;111:524-529.

2. Stephan S, Wang TD Asymmetric nasal tip. Facial Plast Surg. 2012 Apr; 28(2):177-86. Epub 2012 May 6.

3. Daniel RK. Rhinoplasty: Creating an aesthetic tip. PlastReconst Surg.1987;80:775.

4. Friedman O, Koch CA, Smith WRFunctional support of the nasal tip.Facial Plast Surg. 2012 Apr; 28(2):225-30. Epub 2012 May 6.

5. Yeh CC, Williams EF Cosmetic and functional effects of cephalic malposition of the lower lateral cartilages: a facial plastic surgical case study.3rd.Otolaryngol Clin North Am. 2009 Jun; 42(3):539-46.

6. Haack J, Papel ID.Caudal septal deviation: OtolaryngolClin North Am. 2009 Jun; 42(3):427-36.

7. Tebbetts JB. Shaping and positioning the nasal tip without structural disruption: a new, systematic approach. PlastReconst Surg.1994;94:61-77.

8. Daniel RK. Rhinoplasty: a simplified, three-stitch open tip suture technique, I: primary rhinoplasty. PlastReconst Surg. 1999;103:1491-1502.

9. Park SS. The flaring suture to augment the repair of the dysfunctional nasal valve. PlastReconst Surg. 1998;101:11201122.

10. Potter JK.Correction of the crooked nose:Oral MaxillofacSurgClin North Am. 2012 Feb; 24(1):95-107.

11. Antunes MB, Goldstein SA.Surgical approach to nasal valves and the midvault in patients with a crooked nose: Facial Plast Surg. 2011 Oct; 27(5):422-36. Epub 2011 Oct 25.

12. Pearlman S, Baratelli RAvoiding complications of the middle vault in rhinoplasty.Facial Plast Surg. 2012 Jun; 28(3):310-7. Epub 2012 Jun 21.

13. Tardy ME Jr, Chen E. Transdomal suture refinement of the nasal tip. FacPlast Surg. 1987;4:317-326.

14. Sykes JM, Kim JE, Shaye D, BoccieriA. The importance of the nasal septum in the deviated nose: A.FacialPlast Surg. 2011 Oct; 27(5):413-21. Epub 2011 Oct 25. 